\title{
Erratum: Technology and education: Challenges and opportunities
}

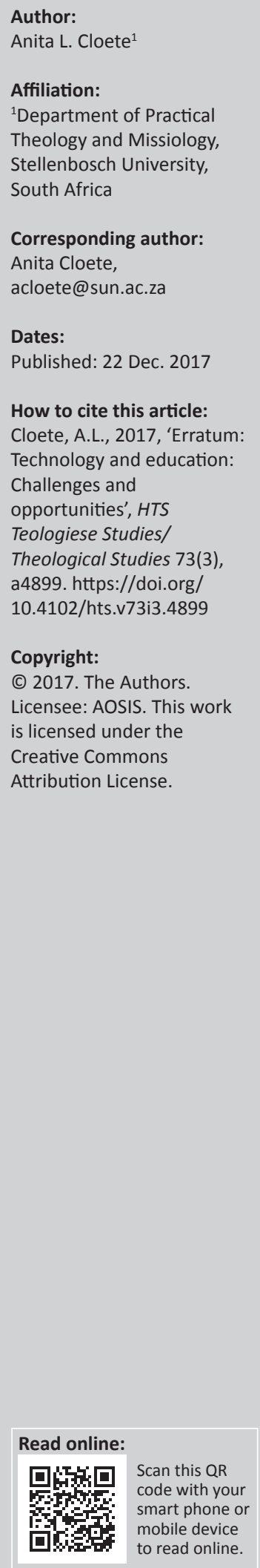

Scan this QR
code with your
smart phone or
mobile device
to read online.

The article was incorrectly categorised as part of Volume 73, Issue 4 of 2017. The article category is hereby corrected as a publication of Volume 73, Issue 3 of 2017. This correction does not alter the study's findings of significance or overall interpretation of the study results. The editor apologises for any inconvenience caused. 